\title{
PLC-B2 is highly expressed in breast cancer and is associated with a poor outcome: A study on tissue microarrays
}

\author{
VALERIA BERTAGNOLO ${ }^{1}$, MASCIA BENEDUSI ${ }^{1}$, PATRIZIA QUERZOLI $^{2}$, MASSIMO PEDRIALI $^{2}$, \\ EROS MAGRI ${ }^{2}$, FEDERICA BRUGNOLI ${ }^{1}$ and SILVANO CAPITANI ${ }^{1,3}$ \\ ${ }^{1}$ Signal Transduction Unit, Laboratory of Cell Biology, Section of Human Anatomy, Department of Morphology and Embryology, \\ ${ }^{2}$ Section of Anatomy, Histology and Pathological Cytology, Department of Experimental and Diagnostic Medicine, \\ ${ }^{3}$ MIUR ICSI (Interdisciplinary Center for the Study of Inflammation), University of Ferrara, Ferrara, Italy
}

Received October 24, 2005; Accepted December 2, 2005

\begin{abstract}
Despite the identification of many putative biomarkers in breast cancer, a specific pattern of proteins to be used as a prognosticator is not well defined. A growing body of evidence supports the role of phospholipase C (PLC) in the invasion and metastasis of different tumors, including breast cancer. To assess whether the expression of specific PLC isoforms correlates with malignancy-related features of human breast tumors and, hence, could have prognostic significance, an immunohistochemical analysis of PLC- 32 was performed on tissue microarrays and the relationship between PLC- 32 expression and biological and clinicopathological factors was assessed. The analysis of 77 samples of breast tumors with different histotypes revealed that PLC- $\$ 2$ is highly expressed in a large majority of the analyzed cancer tissue, particularly ductal and lobular carcinomas, in comparison with normal breast. The expression of PLC- 32 in primary tumors correlated with size, proliferation index and final grade, while no significant relationship was observed with nodal status or estrogen receptor levels, or with the expression of tumor suppressor p53. Remarkably, high PLC- 32 levels in primary tumors predict an unfavourable prognosis, suggesting the contribution of this protein to the progression of human mammary carcinomas. Our data indicate that PLC-B2 expression correlates highly with breast cancer malignancy and suggest that it can be included, as an independent marker, among the prognostic indicators in current use.
\end{abstract}

Correspondence to: Dr Silvano Capitani, Signal Transduction Unit, Laboratory of Cell Biology, Section of Human Anatomy, Dept. of Morphology and Embryology, Via Fossato di Mortara 66, 44100 Ferrara, Italy

E-mail: cps@dns.unife.it

Key words: breast cancer, phospholipase C- 32 , tissue microarrays, tumor markers, prognostic factors

\section{Introduction}

Breast cancer is the most common form of malignancy and the second leading cause of cancer death among women in Western industrial countries (1-3). The high incidence and aggressive biological behavior of this tumor constitute a strong stimulus for identification of new molecular targets for anticancer therapies.

Like most human neoplasms, breast cancer has aberrations in signal transduction elements that can lead to increased proliferative potential, sustained angiogenesis, apoptosis inhibition and tissue invasion and metastasis $(4,5)$. Despite relevant research, the nature of the cellular and molecular changes that lead to breast cancer remains poorly understood, and the assessment of a specific pattern of proteins to be used as a prognosticator is far from satisfactory.

Among the molecules implicated in the intracellular signal transduction machineries, a number of studies indicate that the phosphoinositide-dependent phospholipase C (PLC) is involved in tumorigenic features of a wide variety of tissues (6-17). For instance, an increased expression of PLC- $\gamma 1$ was reported in colon carcinomas (9) as well as in lymphomas (17) and the neoplastic evolution of human gastric mucosa is characterized by an increased expression of PLC- $\delta 2$ (12). At variance, neuronal and neuroendocrine tumors are characterized by modified amounts of the $\beta 3$ isozyme (14).

Concerning PLC in breast cancer, it has been demonstrated that the $\gamma 1$ isozyme is expressed at levels higher than in normal tissue (6). This suggests that upregulation of PLC- $\gamma 1$ is related to the growth factor-mediated tumor cell migration and invasiveness (18-20). Furthermore, PLC- $\delta 4$ is highly expressed in about $25 \%$ of human breast tumor and its upregulation enhances cell proliferation of low tumorigenic breast cancer-derived cells (16).

Proteins whose amounts are altered in neoplastic cells are natural candidate molecular markers for correlation with tumor features. Even if a role of PLC in modulating the motility and invasiveness of tumor cells has been reported (18), the fate of the different PLC isozymes in tumoral transformation of breast cells, as well as their correlation with prognostic factors, has not been explored. 
Concerning the prognostic value of specific PLC isoforms, we have recently demonstrated that the expression level of PLC- 32 is a sensitive marker to determine the responsiveness of patients with acute promyelocytic leukemia (APL) to retinoid-based therapy and that it may allow the identification of a better strategy for the treatment of each APL patient at diagnosis or in case of relapse (13).

Here, we have analyzed the expression of PLC- 32 in breast tumoral cells, using tissue microarrays composed of breast cancer specimens and normal epithelia. By analyzing the relationship between PLC- 32 level and biological and clinico-pathological factors, we have found that the expression of PLC- 32 is upregulated in the large majority of breast cancer samples and that high amounts of this PLC isozyme are closely correlated to poor prognosis in human breast carcinoma.

\section{Materials and methods}

Cell lines. The breast cancer-derived cell lines, MDA-MB-231 and MCF-7, were purchased from the American Type Collection (Rockville, MD). The low tumorigenic BT-474 cell line was from ICLC (Genova, Italy). MDA-MB-231 and MCF-7 were grown in Dulbecco's modified Eagle's medium (DMEM) (Gibco-BRL, Grand Island, NY) supplemented with $10 \%$ fetal calf serum (FCS, Gibco-BRL) and BT-474 was maintained in RPMI-1640 growth medium (Gibco-BRL) supplemented with $10 \%$ fetal calf serum, $1 \mathrm{mM}$ Na pyruvate, $0.01 \mathrm{mg} / \mathrm{ml}$ bovine insulin, in $94 / 6 \%$ air $/ \mathrm{CO}_{2}$ atmosphere. Subconfluent cells were counted daily and cell morphology was evaluated using an inverted phase-contrast microscope (Nikon, Japan).

Immunochemical analysis. Cells were harvested when 70$80 \%$ confluent, washed twice with cold PBS containing $1 \mathrm{mM}$ $\mathrm{Na}_{3} \mathrm{VO}_{4}$ and lysed with a buffer containing $50 \mathrm{mM}$ Tris- $\mathrm{HCl}$ pH 7.4; $1 \%$ Nonidet P-40 (NP-40); $0.25 \%$ sodium deoxycholate; $150 \mathrm{mM} \mathrm{NaCl} ; 1 \mathrm{mM}$ ethylenglycol-bis (ß-aminoethylethen)-N, N'-tetraacetic acid (EGTA); $1 \mathrm{mM}$ phenylmethylsulfonyl fluoride (PMSF); $1 \mu \mathrm{g} / \mathrm{ml}$ each Aprotinin and Leupeptin and $1 \mathrm{mM} \mathrm{Na}_{3} \mathrm{VO}_{4}$ (all from Calbiochem, La Jolla, $\mathrm{CA})$. After $1 \mathrm{~h}$ at $4^{\circ} \mathrm{C}$, the insoluble materials were removed and supernatant ( $1 \mathrm{mg}$ protein) was incubated with rabbit antibodies against human PLC- $\beta 1,-\beta 2,-\beta 3$ and $-\beta 4$ isoforms (Santa Cruz Biotechnology, Santa Cruz, CA), respectively. After addition of protein A-Sepharose (Pharmacia, Uppsala, Sweden), the immunoprecipitates were washed four times with lysis buffer and resuspended in Laemmli's sample buffer.

Immunoprecipitates were separated on $7.5 \%$ polyacrylamide denaturing gels and blotted to nitrocellulose membranes (Amersham Life Science, Little Chalfont, UK). The membranes were then incubated with the correspondent anti-PLC antibodies, as previously reported (13), and the final detection was performed using the ECL system (Perkin-Elmer, Boston, MA), according to the manufacturer's instructions. Densitometric analysis was performed on the ImageQuant TL (Amersham Bioscience, Little Chalfont, UK).

Patients and clinical and histopathological features. The current study included 77 primary infiltrating breast cancers and 10 samples of normal breast tissue obtained from the
Department of Experimental and Diagnostic Medicine of the University of Ferrara (Ferrara, Italy), after informed consent according to the Helsinki declaration of 1975.

All patients were treated with surgery for primary breast cancer and underwent axillary lymph node dissection. None of the patients received neoadjuvant treatment or had distant metastasis at the time of primary surgery. The median age of patients at diagnosis was 57.8 years (range, 32-84 years; SD, 12.05 years). Fifty-eight patients $(75.3 \%)$ were postmenopausal and the median number of axillary lymph nodes per case was 20.2 (range, 10-44; SD, 8.221). The breast cancers were classified according to the WHO histological classification of tumors (21) and histological grading was performed using Elston and Ellis criteria (21) (Table I).

Follow-up data were available for all patients (mean followup time, 9.46 years; range, 8-11 years; SD, 1.13 years). Of the investigated patients, $32(41.6 \%)$ died of breast cancer, $40(51.94 \%)$ were alive and without relapse and $5(6.5 \%)$ were alive with a relapse at the time of this report.

Tissue microarrays (TMAs) preparation. Tumor sections were made from each paraffin embedded block to define a representative area and reviewed by an experienced pathologist (Patrizia Querzoli). Core cylinders with a diameter of $4 \mathrm{~mm}$ were then punched from selected areas of each 'donor' block using an 'AcuPunch' (Acuderm Inc. Ft. Lauderdale, FL) and brought into an acceptor paraffin block with a 24-hole template (23 tumor cylinders and 1 topographic sample).

Immunohistochemical analysis of tumor markers. TMA sections were used for immunostaining of estrogen receptor (ER) by using the anti-ER $\alpha$ 6F11 antibody (Neo Markers, Fremont, CA) and progesterone receptor (PR) by using the anti-PR 1A6 (Neo Markers), as previously reported (23).

Proliferative index (PI) was assessed using anti-MIB-1 antibody (Biomeda, Foster City, CA), HER-2/NEU protein (Pathway HER-2 CB11, Ventana Medical System, Tucson, AZ) and p53 (D07, Neo Markers) were stained with the correspondent antibodies, as previously described (22). All immunostainings were performed using an automated immunostainer (Ventana) and the stained samples were analyzed using a computerized image analysis system (Eureka-Menarini, Florence, Italy). Only tumor cells with distinct nuclear immunostaining for ER, PR, PI and p53 were recorded as positive (23). Only membrane staining was taken into account for HER-2/NEU positivity, and expression of HER-2 was scored according to Pathway HER-2 CB11 instructions.

Immunohistochemical analysis of PLC- $\beta 2$ expression. For analysis of PLC-B2 expression, formalin-fixed, paraffinembedded arrays were deparaffinized by means of the clearing agent Bioclear (Bio-Optica, Milan, Italy), rehydrated in distilled water through graded alcohols (ethanol 100, 95 and 70\%, respectively) and subjected to immunohistochemical analysis with an anti-PLC- $\beta 2$ antibody using the Ultraystain PolyvalentHRP immunostaining kit (YLEM, Rome, Italy). In particular, the slides were incubated in $3 \%(\mathrm{v} / \mathrm{v}) \mathrm{H}_{2} \mathrm{O}_{2}$ and the endogenous peroxidase was blocked with Super Block reagent (YLEM). Afterwards, the arrays were incubated at room temperature for 90 min with anti-PLC-ß2 rabbit polyclonal IgG (1:100 in 
Table I. Main characteristics of 77 breast primary tumors.

\begin{tabular}{lcc}
\hline Primary breast lesions & $\mathrm{n}$ & $\%$ \\
\hline Histotypes & & \\
Ductal & 60 & 77.9 \\
Lobular & 10 & 13.0 \\
Special & & \\
$\quad$ Medullary & 2 & 2.6 \\
$\quad$ Tubular & 3 & 3.9 \\
Mucoid & 2 & 2.6 \\
Size (cm) & & \\
$\leq 2$ & & 58.4 \\
$>2$ & 45 & 41.6
\end{tabular}

Lymph node status

$\begin{array}{lrr}\text { pN0 } & 35 & 45.4 \\ \text { pN1mi } & 24 & 31.2 \\ \text { pN1bi } & 3 & 3.9 \\ \text { pN1bii } & 15 & 19.5\end{array}$

Histological grade

G1

$\mathrm{G} 2$

Proliferation index

$$
\leq 13
$$

$>13$

ER (\% positive nuclei)

$\begin{array}{ll}\leq 10 \% & 18 \\ >10 \% & 49\end{array}$

PR (\% positive nuclei)

$$
\begin{array}{ll}
\leq 10 \% & 17 \\
>10 \% & 50
\end{array}
$$

HER-2 (\% positive cells)

$\begin{array}{lll}\leq 10 \% & 41 & 61.2 \\ >10 \% & 26 & 38.8\end{array}$

P53 (\% positive nuclei)

$\begin{array}{lll}\leq 10 \% & 34 & 51.5 \\ >10 \% & 32 & 48.5\end{array}$

pN0, node-negative patients; pN1mi, metastasis $\leq 0.2 \mathrm{~cm}$; pN1bi, metastasis $>0.2 \mathrm{~cm}$ in $1-3$ lymph nodes; $\mathrm{pN} 1$ bii, 4 or more metastatic lymph nodes.

$10 \mathrm{mM}$ Tris- $\mathrm{HCl}, \mathrm{pH} 8.0 ; 150 \mathrm{mM} \mathrm{NaCl}$ ). The slides were then incubated for $10 \mathrm{~min}$ at room temperature with antipolyvalent biotinylated antibody and, after rinsing in the same buffer, streptavidin-HRP was applied for $10 \mathrm{~min}$. The antibody

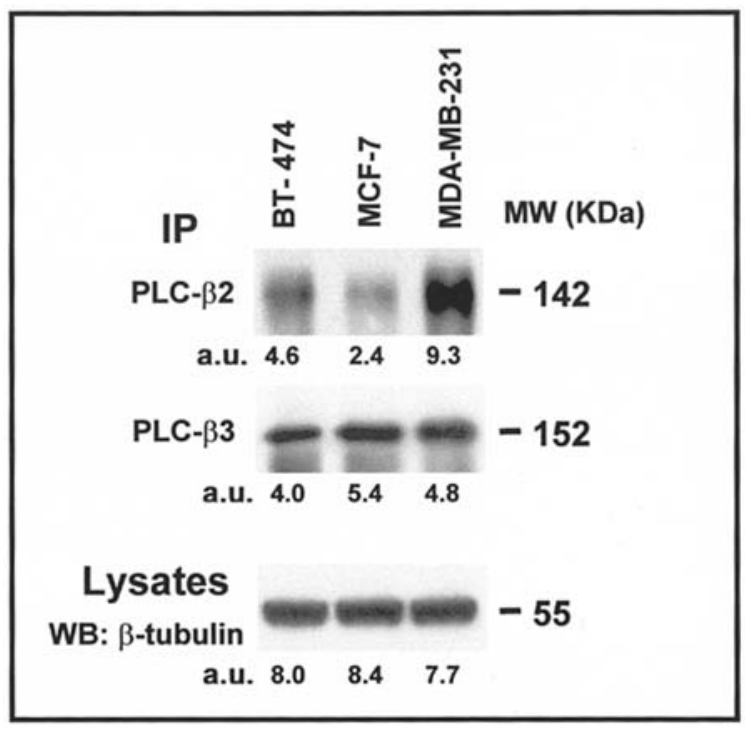

Figure 1. Analysis of PLC- $\beta$ isoforms in breast-cancer derived cells. AntiPLC- 32 and anti-PLC- 33 immunoprecipitates from the different cell lines were subjected to Western blot analysis with the corresponding antibodies. Lysates from the same cells were analyzed for $ß$-tubulin content. Densitometric analysis of autoradiograms was performed and reported as arbitrary units (a.u.). The data are representative of 3 separate experiments, performed in duplicate.

localization was detected by the addition of substrate/ chromogen mix (AEC Cromogeno Kit, YLEM) and the tissue microarrays sections were finally counterstained with Mayer's hemallume solution and rinsed for approximately $10 \mathrm{~min}$ in tap water. Negative controls were obtained by omitting the primary antibody.

Each tissue sample, after hybridization with the anti-PLCß2 antibody, was analyzed by an optical microscope (Carl Zeiss Axiophot 100) and the stain intensity was estimated on a four-step scale by means of analysis of acquired images. For all samples, three different areas, each containing approximately 100 cells, were analyzed and tumors were categorized according to arbitrarily defined criteria into four groups, including 'negative', 'weak', 'moderate' and 'strong' staining. As a general criterion, the cut-offs were selected to facilitate reproducibility on the different microarrays.

Statistical analysis. Statistical analysis was performed using the SPSS package (SPSS Inc., Chicago, IL) implemented on a Windows XP-based PC. Correlations and differences were analyzed using a non-parametric model ( $\chi^{2}$ test). The clinical follow-up analysis for overall survival and relapse-free interval time (OS and RFI respectively) was performed using Kaplan and Meier analysis.

\section{Results}

PLC- $\beta$ expression in human breast cancer-derived cell lines. In this work we firstly evaluated the presence and the expression level of the PLC- $\beta$ subfamily in human breast cancer-derived cell lines with different phenotype and invasiveness. Immunochemical analysis demonstrated that, while PLC- $\beta 1$ and PLC- $\$ 4$ are not expressed (data not shown), PLC- 33 is present in all cell lines, without significant differences due to invasiveness (Fig. 1). On the contrary, PLC- 32 was present 

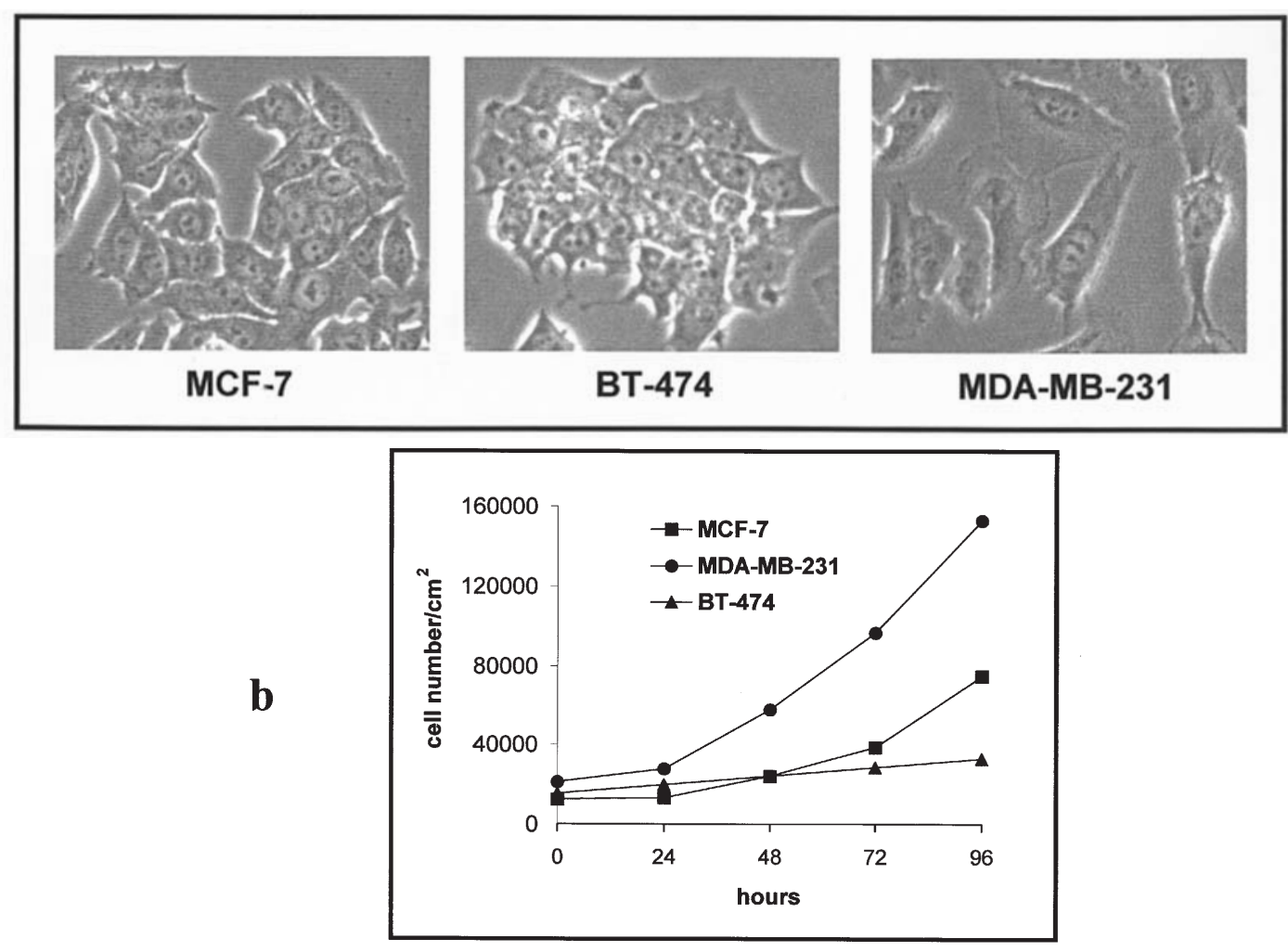

Figure 2. Morphological and proliferative properties of breast cancer derived cell lines. a, phase-contrast images of breast cancer-derived cell lines growing on plastic dishes (magnification x40). b, cell lines were grown in subconfluent conditions for $96 \mathrm{~h}$ and collected daily for counting of viable cells.

to a large extent in the highly invasive breast cancer cell line MDA-MB-231, while a lower amount was expressed by the weakly invasive BT-474 and even less by the epithelial-like MCF-7 cells (Fig. 1).

As reported (24), the weakly invasive MCF-7 cells are luminal epithelial-like polygonal cells that grow as interconnected colonies (Fig. 2a). The poorly invasive BT-474 cell line, characterized by a weakly luminal epithelial-like phenotype, accumulated in clusters of closely attached cells, reaching confluence only rarely (Fig. 2a). Clearly distinct from these two cell types, the highly invasive MDA-MB-231 cells exhibit a fibroblastoid phenotype and grow as colonies with large projections (Fig. 2a). The proliferation rate of all the explored cell lines is reported in Fig. 2b, which confirms that the highly invasive MDA-MB-231 cells grow much more rapidly than the less invasive MCF-7 and BT-474 cell types.

$P L C-\beta 2$ expression in human breast carcinomas. Since PLC- $\beta 2$ is variably expressed in cell lines according to their proliferation rate and invasiveness, we investigated its distribution in both normal mammary tissue and primary breast tumors with different histo-pathological characteristics.

Immunohistochemical studies, performed by using breast cancer TMAs containing tumor samples and control tissue sections, indicated that PLC- $\$ 2$ is expressed, to a variable extent, in almost all normal breast tissue and tumor samples. Any degree of staining was considered positive and the amount of protein was quantified as reported in Materials and methods and classified as 'weak', 'moderate' or 'strong' staining. Based on this classification, samples from normal breast
(Fig. 3a) were $20 \%$ negative and $80 \%$ weakly stained while tumor samples where $5.3 \%$ negative, $22 \%$ weakly, $37.7 \%$ moderately and $35 \%$ strongly stained, respectively.

Carcinomas from all histological types stained positive for PLC- $\$ 2$ and, remarkably, the staining intensity correlated with the morphological differentiation level of the different tumors (Fig. 3b-d). In fact, weak staining (Fig. 3b) is displayed by tumors that retain a differentiated organization with ductlike structures, moderate staining (Fig. 3c) is present in poorly differentiated tumors with solid duct-like structures and a strong intensity (Fig. 3d) was shown by undifferentiated tumors with no ductal organization.

Concerning the localization of PLC-B2 inside tumor tissue, the presence of highly stained, moderately positive and weakly positive cells in the same sample (Fig. 3e) confirmed the specific reaction of the employed antibody and the necessity to evaluate, for each sample, a relatively large number of cells.

Biological and clinico-pathological correlation with PLC- $\beta 2$ expression. As reported in Table II, PLC- 32 expression was significantly higher in ductal and lobular than in special carcinomas, in which the number of negative and weakly stained samples is relatively elevated $(77.8 \%, \mathrm{P}=0.007)$. The expression of PLC- 32 also correlated with tumor size $(\mathrm{P}=0.05)$, since $87.1 \%$ of tumors $>2 \mathrm{~cm}$ are moderately or strongly stained.

PLC- $\beta 2$ expression did not correlate to any statistical significance $(\mathrm{P}=0.754)$ with lymph nodal status. On the other hand, high levels of PLC- 32 were found in primary tumors 


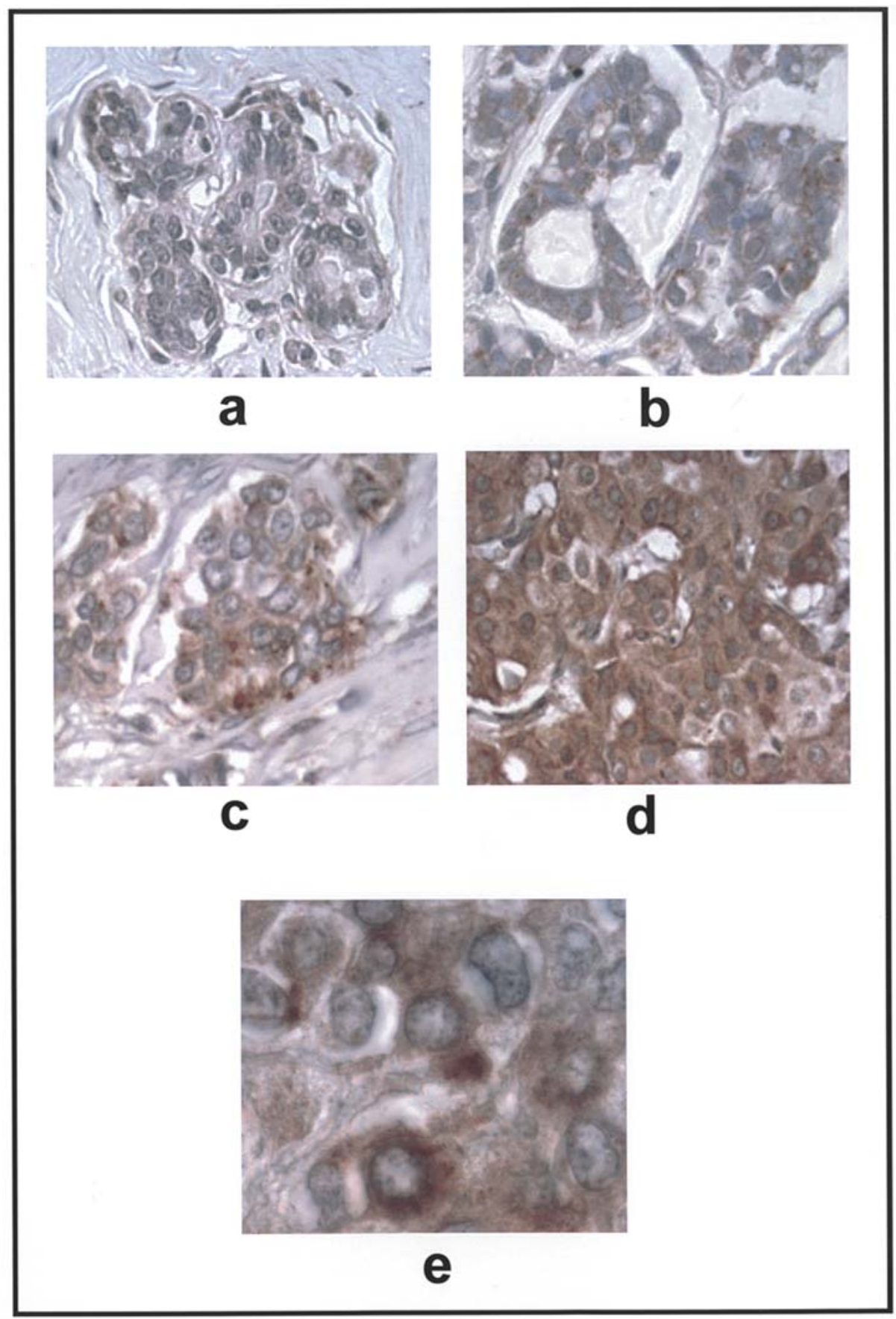

Figure 3. Immunohistochemical analysis of PLC-ß2 expression on sections of healthy and tumoral human breast tissues. Deparafinized TMA sections were incubated with polyclonal anti-PLC- 32 antibody. a, normal breast tissue; b-d, ductal tumours with respectively weak, moderate and strong staining. Magnification $\mathrm{x} 40$. e, magnified section (x100) of a strongly stained ductal sample to note the specificity of the immunoreaction.

from patients with metastasis in lymph nodes $>0.2 \mathrm{~cm}$. Remarkably, $86.6 \%$ of tumors from patients with 4 or more involved lymph nodes show a moderate or strong staining intensity.

Furthermore, PLC- 32 expression closely correlated with tumor grading $(\mathrm{P}<0.001)$, with an increase of staining intensity from grade 1 to grade 3 . In particular, $60 \%$ of mitotic grade 2 and $70 \%$ of mitotic grade 3 samples, respectively, were strongly stained. Remarkably, all samples with final grade 3 fall into the moderate and strong categories of staining and $82.6 \%$ of tumors with final grade 3 show a strong staining intensity.
The close correlation between PLC- $\$ 2$ level and final grade can be further appreciated in Fig. 4, which shows that $100 \%$ of negative samples are final grade $1,70.6 \%$ of the weakly stained samples are grade 1 and none are grade 3,78.6\% of moderately stained samples show final grade 2 and, of the strongly stained samples, $70.4 \%$ are grade 3 and only $14.8 \%$ are grade 1 or 2 .

PLC-B2 expression was then analyzed in relationship to a set of the most common histological parameters used to predict the responsiveness to antitumoral therapies and prognostic factors (Table III). PLC- 32 expression significantly correlated 
Table II. Correlation of PLC-\$2 expression with clinico-pathological factors in invasive breast cancer.

\begin{tabular}{|c|c|c|c|c|c|}
\hline Features & Negative $(\%)$ & Weak staining (\%) & Moderate staining (\%) & Strong staining (\%) & P-value \\
\hline Histotypes & & & & & 0.007 \\
\hline Ductal & 1.7 & 15.5 & 39.7 & 43.1 & \\
\hline Lobular & 10.0 & 20.0 & 40.0 & 30.0 & \\
\hline Special & 22.2 & 55.6 & 22.2 & 0.0 & \\
\hline Size (cm) & & & & & 0.05 \\
\hline$\leq 2$ & 4.4 & 33.3 & 33.3 & 28.9 & \\
\hline$>2$ & 6.5 & 6.5 & 41.9 & 45.2 & \\
\hline Nodal status & & & & & 0.754 \\
\hline pNO & 8.6 & 25.7 & 37.1 & 28.6 & \\
\hline $\mathrm{pN} 1 \mathrm{mi}$ & 4.2 & 25.0 & 37.5 & 33.3 & \\
\hline pN1bi & 0.0 & 0.0 & 66.7 & 33.3 & \\
\hline pN1bii & 0.0 & 13.3 & 33.3 & 53.3 & \\
\hline Grading & & & & & $<0.001$ \\
\hline \multicolumn{6}{|l|}{ Mitotic grade } \\
\hline 1 & 9.8 & 26.8 & 51.2 & 12,2 & \\
\hline 2 & 0.0 & 24.0 & 16.0 & 60.0 & \\
\hline 3 & 0.0 & 0.0 & 30.0 & 70.0 & \\
\hline Nuclear grade & & & & & $<0.001$ \\
\hline 1 & 17.4 & 43.5 & 17.4 & 21.7 & \\
\hline 2 & 0.0 & 24.1 & 55.2 & 20.7 & \\
\hline 3 & 0.0 & 0.0 & 33.3 & 66.7 & \\
\hline Tubular grade & & & & & $<0.001$ \\
\hline 1 & 21.1 & 52.6 & 26.3 & 0.0 & \\
\hline 2 & 0.0 & 28.6 & 21.4 & 50.0 & \\
\hline 3 & 0.0 & 7.0 & 46.5 & 46.5 & \\
\hline Final grade & & & & & $<0.001$ \\
\hline 1 & 18.2 & 54.5 & 9.1 & 18.2 & \\
\hline 2 & 0.0 & 16.1 & 71.0 & 12.9 & \\
\hline 3 & 0.0 & 0.0 & 17.4 & 82.6 & \\
\hline
\end{tabular}

Tissue microarrays containing 77 invasive breast cancers were subjected to immunohistochemical analysis with an anti-PLC- 32 antibody and the staining corresponding to protein levels was correlated with pathological features of the different tumors. pN0, node-negative patients; pN1mi, metastasis $\leq 0.2 \mathrm{~cm}$; pN1bi, metastasis $>0.2 \mathrm{~cm}$ in $1-3$ lymph nodes; pN1bii, $\geq 4$ metastatic lymph nodes.

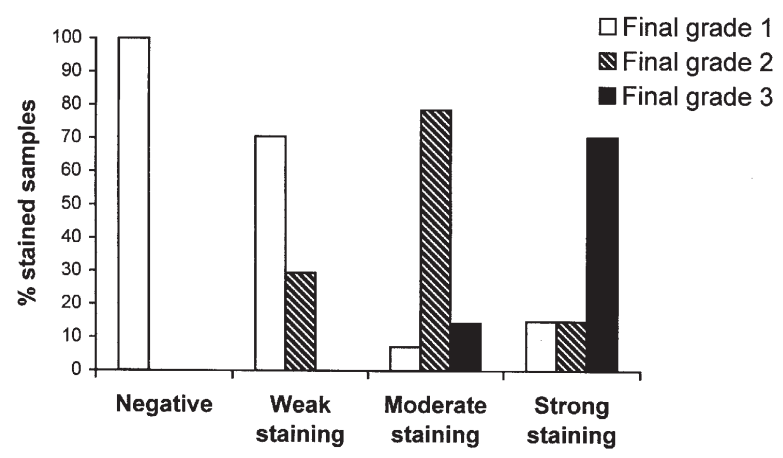

Figure 4. Correlation between staining intensity (PLC- 32 expression) and final tumour grading. Percentage of samples with different levels of PLC- 32 staining inside the 3 groups of tumor final grade.
$(\mathrm{P}=0.031)$ with proliferating index, measured by MIB-1 staining, since $82 \%$ of tumors with MIB-1 $>13$ show moderate or strong staining intensity. On the contrary, no statistically significant correlation was observed between PLC- 32 expression and positivity to estrogen receptor (ER) and progesterone receptor (PR). At any rate, $83 \%$ of tumors negative for at least one of the ER and PR present a moderate or strong staining intensity. At variance, and even though not statistically significant $(\mathrm{P}=0.242)$, an elevated $\mathrm{PLC}-32$ amount (moderate or strong staining) is present in $69.2 \%$ of samples positive for the HER-2 member of the epidermal growth factor receptor (EGFR) family (Table III). Even when $43.8 \%$ of p53positive samples showed a strong PLC- $\beta 2$ staining intensity, a significant correlation with PLC- 32 expression was not found $(\mathrm{P}=0.603)$ (Table III). 
Table III. Correlation of PLC-\$2 expression with biological markers in invasive breast cancers.

\begin{tabular}{|c|c|c|c|c|c|}
\hline Markers & Negative (\%) & Weak staining $(\%)$ & Moderate staining (\%) & Strong staining $(\%)$ & P-value \\
\hline MIB-1 & & & & & 0.031 \\
\hline$\leq 13$ & 10.7 & 39.3 & 28.6 & 21.4 & \\
\hline$>13$ & 2.6 & 15.4 & 33.3 & 48.7 & \\
\hline ER & & & & & 0.233 \\
\hline- & 5.6 & 11.1 & 27.8 & 55.6 & \\
\hline+ & 6.1 & 30.6 & 32.7 & 30.6 & \\
\hline PR & & & & & 0.365 \\
\hline- & 5.9 & 11.8 & 29.4 & 52.9 & \\
\hline+ & 6.0 & 30.0 & 32.0 & 32.0 & \\
\hline HER-2 & & & & & 0.242 \\
\hline- & 7.3 & 24.4 & 39.0 & 29.3 & \\
\hline+ & 3.8 & 26.9 & 19.2 & 50.0 & \\
\hline P53 & & & & & 0.603 \\
\hline- & 5.9 & 26.5 & 38.2 & 29.4 & \\
\hline+ & 6.3 & 25.0 & 25.0 & 43.8 & \\
\hline
\end{tabular}

Tissue microarrays containing 77 invasive breast cancers were subjected to immunohistochemical analysis with an anti-PLC- 32 antibody and the staining corresponding to protein levels was correlated with biological markers of the different tumors.

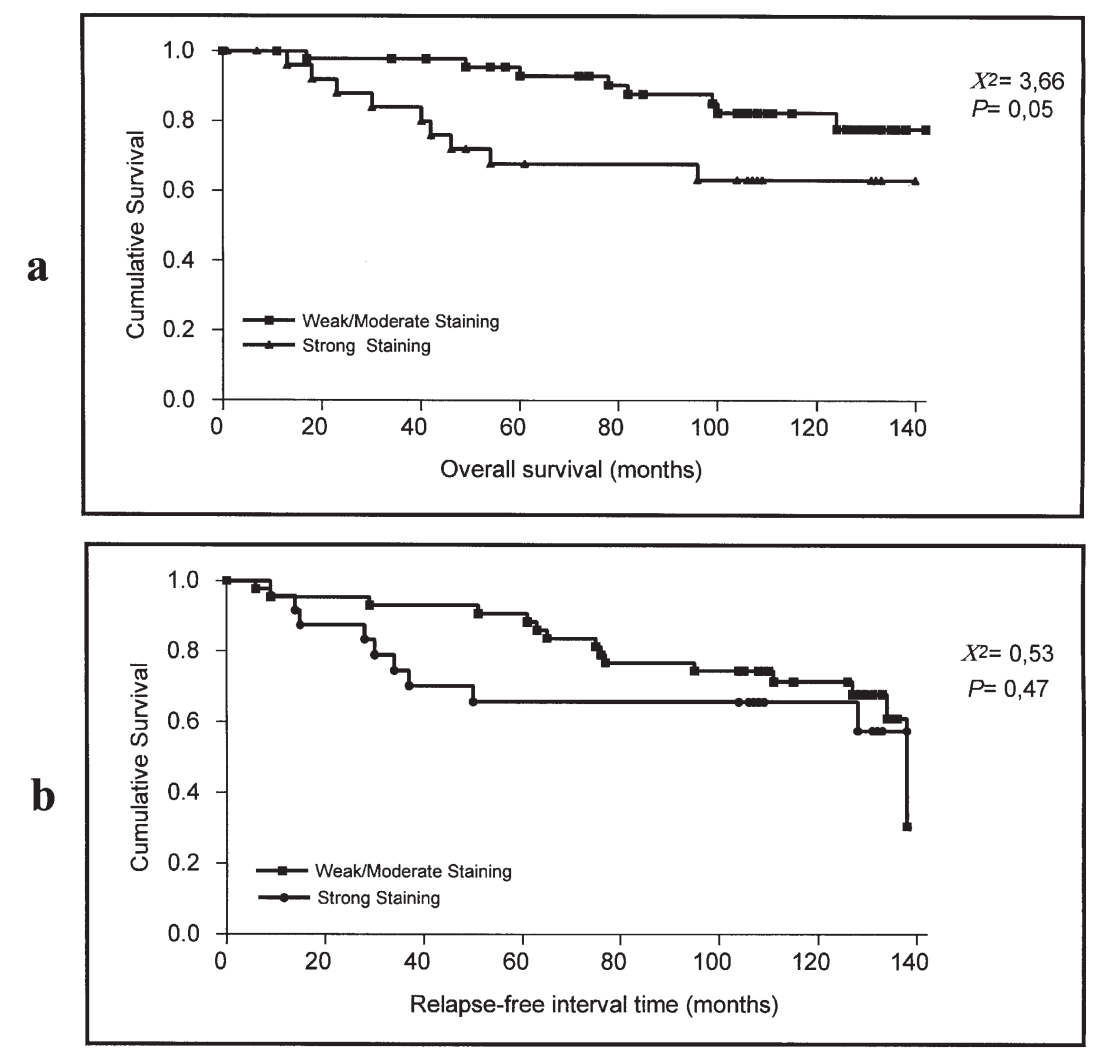

Figure 5. Relationship between PLC-\$2 expression and patient's outcome. Kaplan and Meier plots indicating the relationship between PLC- 32 levels and (a) overall survival and (b) disease-free interval in patients with breast cancer.

Prognostic significance of PLC- $\beta 2$ expression in human breast carcinomas. The prognostic significance of PLC- 32 levels was evaluated in breast cancer samples from patients where clinical follow-up was available (follow-up period of 140 months). 
Analysis of breast cancer-related death was performed and the overall survival Kaplan-Meier plots are shown in Fig. 5a. The data indicate that patients whose primary tumors expressed high levels of PLC- 32 (strong staining) had an overall survival time significantly shorter than those with lower PLC- 32 levels (weak and moderate staining) ( $\mathrm{P}=0.05$ ). In particular, $32.2 \%$ of patients whose primary tumors express high levels of PLC- 32 and only $6.8 \%$ of patients with weakly or moderately stained primary tumors have the probability of a low survival time ( $\leq 5$ years).

We also evaluated the association between PLC- 32 levels and disease-free survival time (Fig. 5b). The results are not statistically significant $(\mathrm{P}=0.47)$ but indicate that patients whose primary breast cancer samples displayed a high staining intensity show a shorter relapse-free interval time. It is worth noting that, 3 years after surgical removal of the primary tumor, $33.3 \%$ of patients whose tumor samples showed high levels of PLC- 32 (strong staining intensity) had relapsed, while 93\% of patients with moderate or weak staining were relapse-free.

\section{Discussion}

The PLC family comprises 11 different isozymes, grouped into four subfamilies $(\beta, \gamma, \delta$ and $\varepsilon$ ) that differ in structure, activation mechanism and tissue distribution $(25,26)$. Experiments with transgenic mice indicate that each isoform is critical to a selected set of functions in developing and adult animals. $\delta$ isoforms are thought to be the evolutionary precursors of the other subfamilies and the $\beta$ and $\gamma$ isozymes have specialized roles only at late stages of development (25).

Mammalian PLC isoforms are differently distributed in the diverse tissues, and their expression is modified in a variety of mammalian tumors. In breast cancer, PLC has been analyzed only occasionally and its involvement in neoplastic transformation is currently poorly understood. So far, the only isoforms described in breast tissue are $\gamma 1$ and $\delta 4$. The $\gamma 1$ isozyme is expressed at levels higher than in normal tissue (6) and this overexpression seems to be related to growth factor-mediated cancer cell migration, since the inhibition of PLC activity blocks proliferation and EGF-driven tumor cell migration and invasiveness $(19,20)$. It has been demonstrated that the forced expression of PLC- $\delta 4$ in low tumorigenic breast cancer-derived cells enhances the proliferation rate (16).

Since it is difficult to obtain highly purified primary breast cancer cells, a large part of the data available on human breast carcinoma has been obtained on breast cancer-derived cell lines. These in vitro cell models often show some modification in respect to the tumor from which they originate; however, they provide an unlimited number of homogenous cells, free of contamination by fibroblast and other tumor stromal cells and maintain substantially unmodified characteristics when cultured in vitro (24). In this study, we report the unprecedented observation that, in addition to the already described $\gamma$ and $\delta$ isozymes, some members of the $\beta$ subfamily of PLC are present in breast cancer-derived cells. We here show that the amount of PLC- 32 is significantly elevated in the highly invasive breast cancer cell line, MDA-MB-231, in comparison to the less tumorigenic BT-474 and MCF-7 cells.

Since PLC- 32 is variably expressed in breast tumor-derived cell lines showing different morphology and invasiveness, suggestive for a potential role in tumor-related cell features, its presence and amount was retrospectively explored in normal and neoplastic breast tissues. The PLC- $\$ 2$ levels were investigated by applying TMA technology, which allowed us to process a large number of normal and tumoral tissue specimens, and facilitated the selection of scoring criteria because the entire section could be used for analysis and the individual selection of single tumor areas is avoided (27-29). Immunohistochemical analysis of 87 human breast samples, 77 of which were from tumors with different histological and clinical characteristics, demonstrated that PLC- $\$ 2$ is poorly expressed in normal tissue and that its amount is significantly higher in almost $95 \%$ of tumor samples.

PLC- 32 is expressed at the highest levels in cells of hematopoietic origin (10), consistently with the role played by this protein in leukocyte signalling and host defences $(30,31)$. The only aberration in PLC- 32 level reported so far characterizes APL-derived cells that are blocked to a poorly differentiated state (32). Both in vitro and in vivo experiments demonstrated that treatments aimed to abolish the differentiation block induce a set of events including the increased expression of PLC- $\$ 2$. More remarkably, the levels of PLC- $\$ 2$ reached by leukemic blasts after in vitro differentiative treatment may predict the response of APL patients to retinoid-based therapies, either at diagnosis or in case of relapse (13), indicating that also the amount of a sole PLC isoform may have a prognostic value.

During the sequential in vivo progression of breast cancer from atypical hyperproliferation to metastatic disease, tumor cells undergo phenotype alterations, including the loss, to a variable extent, of epithelial-like features, and the gain of more aggressive and invasive mesenchymal-like traits $(33,34)$. Accordingly, a weakly luminal epithelial-like phenotype could constitute a transitory step in tumor cell progression from the luminal epithelial-like portrait to the mesenchymallike one (24). In this study, we found that the amount of PLC- $\beta 2$ strongly correlates with some properties of the investigated cell lines, such as proliferation rate and morphological phenotype, suggesting that this enzyme may be involved in regulating the characteristics of immortalized cells, responsible for promotion of cancer cell invasion and metastatic potential. Furthermore, the amount of PLC- 32 correlates with morphological features of the different primary cancers, since weak expression is showed by tumors that retain a differentiated appearance, while a progressively higher amount of protein was revealed in poorly differentiated and undifferentiated tumors. These data are in agreement with the notion that PLC- 32 , in mature organs, is almost exclusively expressed by differentiated hematopoietic cells (10) and suggest that high expression in other tissues, such as breast, may be associated with undifferentiated conditions. Since malignant transformation of mammary tissue produces a number of differently organized morphological features (24), PLC- 32 may have a role in modulating some functions of undifferentiated cells and its amount may reflect the steady state of breast tumors.

Among the parameters currently used to predict the clinical outcome of breast carcinomas, the most important are tumor size, lymph node status and tumor grade (35). In addition, the expression level of several proteins is used to identify tumors 
responding to specific therapies even though, due to the molecular heterogeneity within the tumor categories, the clinical course of any individual patient with breast carcinoma remains difficult to predict (36-38). For this reason, the identification of new molecular markers might help to better stratify patients and guide treatment strategies. In this context and on the basis of the data obtained on both breast cancerderived cells and tumor samples, PLC- $\$ 2$ may represent a good candidate for correlation with the malignant features of human breast cancer.

Our data demonstrate that the expression of PLC-B2 strikingly correlates with histological grade, confirming that the amount of this PLC isoform reflects the differentiative status of tumor cells. High levels of PLC- $\$ 2$ strongly correlate also with the proliferation rates of the studied cell lines, as well as with key risk factors such as high mitotic index and large size of primary tumors. No significant correlations with lymph node status were found, even if an elevated amount of PLC- 32 was observed in primary tumors when a large number of lymph nodes showed metastasis. These data suggest that PLC- 32 might have a role in breast cancer cell proliferation but not in their invasive potential, at variance with the EGFdriven function in cell migration and invasiveness described for PLC- $\gamma 1(18,19)$.

Even though a role in promoting proliferation of breastderived cell lines was already reported for PLC- $\delta 4$, this protein was upregulated in a relatively low percentage of tumors (16) when compared with the almost totality of PLC- 32 overexpressing breast tissue. This suggests that PLC- $\beta 2$ can be regarded as a reliable marker of the status of essentially all breast tumor varieties.

Traditional factors, such as estrogen receptor, progesterone receptor and HER-2, remain the most useful indicators of prognosis and therapeutic treatment in breast cancer (39-41). Tumors can express ER or PR or both, and tumors with expression of both appear to have a better response to antihormonal therapy than tumors with expression of none or of one receptor. We did not find any difference in PLC- $\$ 2$ amount in tumors that express ER or PR, while tumors negative for at least one of the two receptors showed elevated expression of this enzyme, suggesting that a high amount of PLC- $\$ 2$ might be associated with a worse response to therapy.

The overexpression of HER-2 correlates with the pathogenesis and prognosis of breast cancer (42). It is considered an important therapeutic target and different molecular therapies have been developed to target this member of the EGFR family (40). In our study, we found that the majority of HER-2 positive tumors show a large amount of PLC- $\$ 2$, suggesting that overexpression of this protein may be an adverse prognostic factor.

Despite the evidence indicating loss of p53 function in breast cancer, gene mutations occur at a significantly lower frequency in breast carcinoma than in other solid tumors (43). In our study, no correlation was found between the amount of PLC- 32 and the tumor suppressor p53 level inside nuclei of tumor cells, consistent with the current controversy on the role as a prognostic factor assigned to this protein in breast cancer.

Survival analysis of cancer-related death indicates that patients whose primary tumors expressed low levels of PLC- 32 showed an overall survival significantly higher than patients whose primary tumors expressed high levels of protein. In addition, elevated PLC- $\beta 2$ expression of primary breast cancer samples seems to be associated with a shorter relapse-free interval time.

The present study demonstrates, for the first time, that PLC- $\beta 2$ is highly expressed in breast cancer, and that its amount is predictive for tumor progression and cancer mortality. Even if the significance of PLC- 32 in guiding the clinical management of patients with breast cancer remains to be assessed, our results suggest a potential clinical role for PLC- $\$ 2$ as a molecular marker of breast cancer severity.

\section{Acknowledgments}

This research was supported by grants from MIUR Cofin (2003), Ministero della Salute (Programma Speciale Emopoiesi, 2002), FIRB (2001) and the Interdisciplinary Center for the Study of Inflammation (ICSI) to S. Capitani, and local funds from the University of Ferrara (Italy) to V. Bertagnolo and S. Capitani.

\section{References}

1. Hortobagyi GN: Treatment of breast cancer. N Engl J Med 339: 974-841, 1998.

2. Greenlee RT, Hill-Harmon MB, Murray T and Thun M: Cancer statistics 2001. CA Cancer J Clin 51: 15-36, 2001.

3. Wilson CM, Tobin S and Young RC: The exploding worldwide cancer burden: the impact of cancer on women. Int J Gynecol Cancer 14: 1-11, 2004.

4. Oved S and Yarden Y: Signal transduction: molecular ticket to enter cells. Nature 416: 133-136, 2002.

5. Rowinsky EK: Signal events: cell signal transduction and its inhibition in cancer. Oncologist 8: 5-17, 2003.

6. Arteaga CL, Johnson MD, Todderud G, Coffey RJ, Carpenter G and Page DL: Elevated content of the tyrosine kinase substrate phospholipase C-gamma 1 in primary human breast carcinomas. Proc Natl Acad Sci USA 88: 10435-10439, 1991.

7. Martelli AM, Billi AM, Gilmour RS, Neri LM, Manzoli L, Ognibene A and Cocco L: Phosphoinositide signaling in nuclei of Friend cells: phospholipase $\mathrm{C}$ beta down-regulation is related to cell differentiation. Cancer Res 54: 2536-2540, 1994.

8. Iiri T, Homma Y, Ohoka Y, Robishaw JD, Katada T and Bourne HR: Potentiation of Gi-mediated phospholipase C activation by retinoic acid in HL-60 cells. Possible role of $\mathrm{G}$ gamma 2. J Biol Chem 270: 5901-5908, 1995.

9. Nomoto K, Tomita N, Miyake M, Xhu DB, LoGerfo PR and Weinstein IB: Expression of phospholipases gamma 1, beta 1, and delta 1 in primary human colon carcinomas and colon carcinoma cell lines. Mol Carcinog 12: 146-152, 1995.

10. Lee SB, Rao AK, Lee KH, Yang X, Bae YS and Rhee SG: Decreased expression of phospholipase C-beta 2 isozyme in human platelets with impaired function. Blood 88: 1684-1691, 1996.

11. Bertagnolo V, Marchisio M, Capitani S and Neri LM: Intranuclear translocation of phospholipase $\mathrm{C}$ beta2 during HL-60 myeloid differentiation. Biochem Biophys Res Commun 235: 831-837, 1997.

12. Marchisio M, Di Baldassarre A, Angelucci D, et al: Phospholipase $\mathrm{C}$ delta2 expression characterizes the neoplastic transformation of the human gastric mucosa. Am J Pathol 159: 803-808, 2001.

13. Bertagnolo V, Marchisio M, Pierpaoli S, Colamussi ML, Brugnoli F, Visani G, Zauli G and Capitani S: Selective upregulation of phospholipase $\mathrm{C}$-beta2 during granulocytic differentiation of normal and leukemic hematopoietic progenitors. J Leukoc Biol 71: 957-965, 2002.

14. Stalberg P, Granberg D, Carling T, Wilander E, Eriksson B, Gobl A, Akerstrom G, Rastad J, Modlin IM, Oberg K and Skogseid B: In situ RNA-RNA hybridisation of phospholipase C beta 3 shows lack of expression in neuroendocrine tumours. Anticancer Res 23: 2227-2232, 2003. 
15. Lo Vasco VR, Calabrese G, Manzoli L, Palka G, Spadano A, Morizio E, Guanciali-Franchi P, Fantasia D and Cocco L: Inositide-specific phospholipase $\mathrm{C}$ betal gene deletion in the progression of myelodysplastic syndrome to acute myeloid leukemia. Leukemia 18: 1122-1126, 2004.

16. Leung DW, Tompkins C, Brewer J, Ball A, Coon M, Morris V, Waggoner D and Singer JW: Phospholipase C delta-4 overexpression upregulates ErbB1/2 expression, Erk signaling pathway, and proliferation in MCF-7 cells. Mol Cancer 13: $1-15,2004$.

17. Pozzobon M, Marafioti T, Hansmann ML, Natkunam Y and Mason DY: Intracellular signalling molecules as immunohistochemical markers of normal and neoplastic human leucocytes in routine biopsy samples. Br J Haematol 124: 519-533, 2004.

18. Kassis J, Moellinger J, Lo H, Greenberg NM, Kim HG and Wells A: A role for phospholipase C-gamma-mediated signaling in tumor cell invasion. Clin Cancer Res 5: 2251-2260, 1999.

19. Dittmar T, Husemann A, Schewe Y, Nofer JR, Niggemann B, Zanker KS and Brandt BH: Induction of cancer cell migration by epidermal growth factor is initiated by specific phosphorylation of tyrosine 1248 of c-erbB-2 receptor via EGFR. FASEB J 16: 1823-1825, 2002.

20. Katterle Y, Brandt BH, Dowdy SF, Niggemann B, Zanker KS and Dittmar T: Antitumour effects of PLC-gamma1-(SH2)2TAT fusion proteins on EGFR/c-erbB-2-positive breast cancer cells. Br J Cancer 90: 230-235, 2004.

21. World Health Organization Classification of Tumours: Pathology and genetics of tumours of the breast and female genital organs. Tavassoli FA and Devilee P (eds). WHO, IARC, Lyon, 2003.

22. Elston CW and Ellis IO: Pathological prognostic factors in breast cancer. The value of histological grade in breast cancer: experience from a large study with long-term follow-up. Histopathology 19: 403-410, 1991 .

23. Querzoli P, Albonico G, Ferretti S, Rinaldi R, Magri E and Nenci I: Quantitative immunoprofiles of breast cancer performed by image analysis. Anal Quant Cytol Histol 21: 151-160, 1999.

24. Lacroix M and Leclercq G: Relevance of breast cancer cell lines as models for breast tumours: An update. Breast Cancer Res Treat 83: 249-289, 2004.

25. Rebecchi MJ and Pentyala SN: Structure, function, and control of phosphoinositide-specific phospholipase C. Physiol Rev 80: 1291-1335, 2000.

26. Rhee SG: Regulation of phosphoinositide-specific phospholipase C. Annu Rev Biochem 70: 281-312, 2001.

27. Torhorst J, Bucher C, Kononen J, Haas P, Zuber M, Kochli OR, Mross F, Dieterich H, Moch H, Mihatsch M, Kallioniemi OP and Sauter G: Tissue microarrays for rapid linking of molecular changes to clinical endpoints. Am J Pathol 159: 2249-2256, 2001.

28. Zhang D, Salto-Tellez M, Do E, Putti TC and Koay ES: Evaluation of HER-2/neu oncogene status in breast tumors on tissue microarrays. Hum Pathol 34: 362-368, 2003.
29. Grant GM, Bucher C, Kononen J, Haas P, Zuber M, Kochli OR, Mross F, Dieterich H, Moch H, Mihatsch M, Kallioniemi OP and Sauter G: Microarrays in cancer research. Anticancer Res 24: 441-448, 2004.

30. Jiang H, Kuang Y, Wu Y, Xie W, Simon MI and Wu D: Roles of phospholipase $\mathrm{C}$ beta2 in chemoattractant-elicited responses. Proc Natl Acad Sci USA 94: 7971-7975, 1997.

31. Li Z, Jiang H, Xie W, Zhang Z, Smrcka AV and Wu D: Roles of PLC-beta2 and -beta3 and PI3Kgamma in chemoattractantmediated signal transduction. Science 287: 1046-1049, 2000.

32. Lanotte M, Martin-Thouvenin V, Najman S, Balerini P, Valensi F and Berger R: NB4, a maturation inducible cell line with $\mathrm{t}(15 ; 17)$ marker isolated from a human acute promyelocytic leukemia. Blood 77: 1080-1086, 1991.

33. Thompson EW, Paik S, Brunner N, Sommers CL, Zugmaier G, Clarke R, Shima TB, Torri J, Donahue S and Lippman ME: Association of increased basement membrane invasiveness with absence of estrogen receptor and expression of vimentin in human breast cancer cell lines. J Cell Physiol 150: 534-544, 1992.

34. Sommers CL, Byers SW, Thompson EW, Torri JA and Gelmann EP: Differentiation state and invasiveness of human breast cancer cell lines. Breast Cancer Res Treat 31: 325-335, 1994.

35. Schmid P, Wischnewsky MB, Sezer O, Bohm R and Possinger K: Prediction of response to hormonal treatment in metastatic breast cancer. Oncology 63: 309-316, 2002.

36. Allred DC, Harvey JM, Berardo M and Clark GM: Prognostic and predictive factors in breast cancer by immunohistochemical analysis. Mod Pathol 11: 155-168, 1998

37. Sorlie T, Perou CM, Tibshirani R, et al: Gene expression patterns of breast carcinomas distinguish tumor subclasses with clinical implications. Proc Natl Acad Sci USA 98: 10869-10874, 2001.

38. Van de Rijn M, Perou CM, Tibshirani R, Haas P, Kallioniemi O, Kononen J, Torhorst J, Sauter G, Zuber M, Kochli OR, Mross F, Dieterich H, et al: Expression of cytokeratins 17 and 5 identifies a group of breast carcinomas with poor clinical outcome. Am J Pathol 161: 1991-1996, 2002.

39. Sneige N: Utility of cytologic specimens in the evaluation of prognostic and predictive factors of breast cancer: current issues and future directions. Diagn Cytopathol 30: 158-165, 2004.

40. Esteva FJ: Monoclonal antibodies, small molecules, and vaccines in the treatment of breast cancer. Oncologist 9: 4-9, 2004.

41. Hinoda Y, Sasaki S, Ishida T and Imai K: Monoclonal antibodies as effective therapeutic agents for solid tumors. Cancer Sci 95: 621-625, 2004.

42. Nahta R and Esteva FJ: HER-2-targeted therapy: lessons learned and future directions. Clin Cancer Res 9: 5078-5084, 2003.

43. Gasco M, Shami S and Crook T: The p53 pathway in breast cancer. Breast Cancer Res 4: 70-76, 2002. 